\title{
Problem-based learning in optical engineering studies
}

\section{Anna Voznesenskaya}

Anna Voznesenskaya, "Problem-based learning in optical engineering studies," Proc. SPIE 9946, Optics Education and Outreach IV, 994610 (27 September 2016); doi: 10.1117/12.2237170

EDent: SPIE Optical Engineering + Applications, 2016, San Diego, California, United States 


\title{
Problem-based learning in optical engineering studies
}

\author{
Anna Voznesenskaya \\ ITMO University (Russian Federation)
}

\begin{abstract}
Nowadays, the Problem-Based Learning (PBL) is one of the most prospective educational technologies. PBL is based on evaluation of learning outcomes of a student, both professional and personal, instead of traditional evaluation of theoretical knowledge and selective practical skills. Such an approach requires changes in the curricula development. There should be introduced projects (cases) imitating real tasks from the professional life. These cases should include a problem summary with necessary theoretic description, charts, graphs, information sources etc, task to implement and evaluation indicators and criteria. Often these cases are evaluated with the assessment-center method. To motivate students for the given task they could be divided into groups and have a contest. Whilst it looks easy to implement in social, economic or teaching fields PBL is pretty complicated in engineering studies. Examples of cases in the first-cycle optical engineering studies are shown in this paper. Procedures of the PBL implementation and evaluation are described.
\end{abstract}

Keywords: problem-based learning, case-study, educational technologies, learning outcomes, optical engineering

\section{INTRODUCTION}

Modern fast-changing world requires that graduates are able to study new things quickly, adapt easy to new work conditions, operate independently, demonstrate skills in computer technologies and communication, be effective in a team, critical-thinking, creative, responsible, etc. Obviously, that these personal features are to be developed during studies in University through implementation of special problem-based learning (PBL) cases $[1,2]$. Such cases place students into real professional work environment, make them to apply at once theoretical knowledge they have as well as practical skills and personal abilities. PBL cases are especially important at final stages of educational programs - to confirm professional competence level of graduates and give students understanding of their strong and weak features, and their gaps in education. Whilst it looks easy to implement in social, economic or teaching fields PBL is pretty complicated in engineering studies, in particular in optical engineering.

\section{STRUCTURE OF PBL CASES}

PBL cases represent separate projects aimed to demonstrate professional learning outcomes of a student. The structure of PBL cases are similar to real projects, consists of the following main parts (Figure 1): 1) Preamble - short theoretical description of the problem; 2) Task - list of technical requirements; 3) Results - report and presentation; 4) Assessment evaluation indicators and criteria.

Students perform the PBL cases in groups. It provides the complex nature of the PBL cases, motivates students and makes them more competitive. As soon as students have a case they study the theoretical description of the problem and analyze given technical requirements. To get more information they may use any information sources.

In optical engineering PBL cases are usually connected with optical system modeling and design using special mathematical algorithms, commercial software or programming tools. Results of the PBL cases are engineering calculations, plots, schemes, drawings, performance characteristics, etc. These data are shown in the report and presentation. Often there are some technical decisions from a group.

The most complicated part of the PBL case is assessment of results. Generally the assessment concludes in evaluation using special assessment form with indicators and criteria formulated in accordance with recognized recommendations [3] (Table). For this case one the most promising method is the circular assessment $\left(360^{\circ}\right.$ method, assessment-center method). This method requires that in evaluation are involved various participants of the PBL case -

Optics Education and Outreach IV, edited by G. Groot Gregory, Proc. of SPIE Vol. 9946, 994610

(c) 2016 SPIE · CCC code: $0277-786 X / 16 / \$ 18 \cdot$ doi: $10.1117 / 12.2237170$ 
tutor, side participants, and students themselves (Figure 2). It provides the expert evaluation approach. Finally, after processing of the assessment forms each participant receives his own estimation.

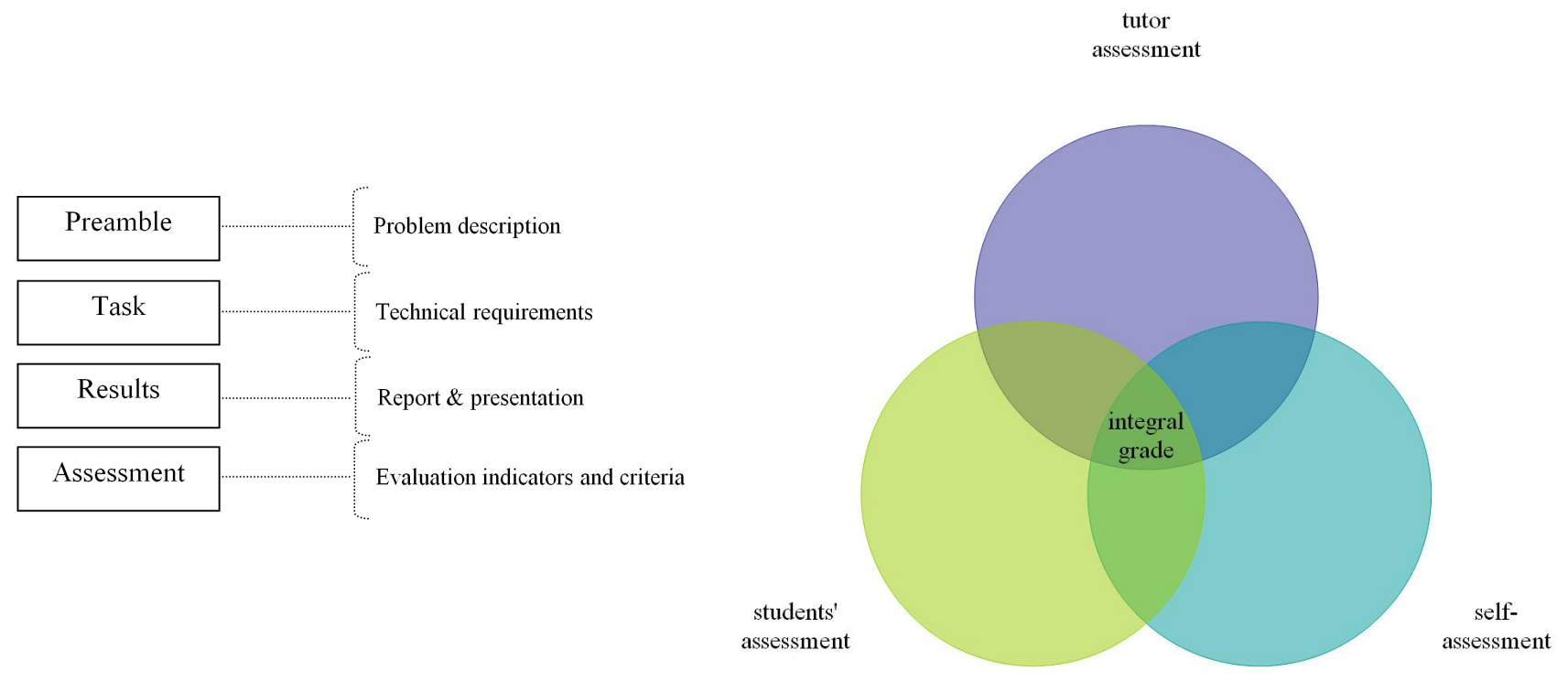

Figure 1. PBL case structure

Figure 2. Circular assessment of learning outcomes

Table. Assessment form example

Student

Group

Expert

\begin{tabular}{|c|c|c|c|c|c|}
\hline \multirow[b]{2}{*}{ No } & \multirow[b]{2}{*}{ Indicators } & \multicolumn{4}{|c|}{ Grade } \\
\hline & & $\begin{array}{c}5 \\
\text { (excellent) }\end{array}$ & $\begin{array}{c}4 \\
\text { (good) }\end{array}$ & $\begin{array}{c}3 \\
\text { (satisfactory } \\
\text { ) }\end{array}$ & $\begin{array}{c}0^{*} \\
\text { (unsatisfactory/ } \\
\text { irrelevant) }\end{array}$ \\
\hline 1 & Analysis of information sources & & & & \\
\hline 2 & Foreign languages & & & & \\
\hline 3 & Base knowledge in professional area & & & & \\
\hline 4 & Base knowledge in neighboring areas & & & & \\
\hline 5 & Problem solving skills and research skills & & & & \\
\hline 6 & Practical skills & & & & \\
\hline 7 & $\begin{array}{l}\text { Computer technologies skills and } \\
\text { application of specific commercial software }\end{array}$ & & & & \\
\hline 8 & Reporting skills & & & & \\
\hline 9 & Public speaking skills & & & & \\
\hline 10 & $\begin{array}{l}\text { Interpersonal communication skills } \\
\text { (teamwork) }\end{array}$ & & & & \\
\hline 11 & Creativity and independent work & & & & \\
\hline 12 & Leadership & & & & \\
\hline 13 & Tolerance and loyalty & & & & \\
\hline 14 & Time-management skills & & & & \\
\hline
\end{tabular}




\section{EXAMPLES OF PBL CASES}

Usually the PBL cases are performed during 4-6 hours. The cases are taken from real projects. It could be composed a database with such PBL cases in the optical engineering. In the following part examples of the PBL cases are shown.

\section{Case 1. Optical system design for photocatalysis module}

\section{Preamble}

Photocatalysis is a perspective method for air purification on a molecular level that provides to design cost-saving and efficient devices. These investigations last actively 10-15 years. In particular, the photocatalysis purification is applied at plants producing explosives, "Boeing" crafts, in residential urban areas and tunnels, hospitals to suppress pathogenic microflora in the air in the treatment of allergic diseases, in pharmaceutical industries and in the destruction of chemical warfare agents, etc. Photocatalysis is defined as the change in the speed or excitation of chemical reactions under the action of light in the presence of the substances (photocatalysts) that absorb light quanta and are involved in chemical transformations of the reaction participants, repeatedly entering them into intermediate interactions and regenerating its chemical composition after each cycle of their interactions. The essence of the method consists in a photocatalytic mineralization of gaseous impurities on the catalyst surface under the action of the soft UV radiation range (wavelength of from 300 to $400 \mathrm{~nm}$ ). The reaction proceeds at room temperature, and contaminants do not accumulate on the filter, and collapse to harmless components - carbon dioxide and water. It is shown that on the surface of the $\mathrm{TiO}_{2}$ photocatalyst by $\mathrm{UV}$ irradiation can be oxidized (mineralized) to $\mathrm{CO}_{2}$ and $\mathrm{H}_{2} \mathrm{O}$ almost any organic compounds.

Until recently, the definite disadvantages of the method carried in the need to replace every 7-8 months the UV lamps and the need for their disposal (demercurization), and high energy costs. However, the beginning of industrial production of solid-state sources of UV radiation - UV light-emitting diodes (UV LEDs) may provide implementation of the photocatalytic purification devices, practically deprived of these disadvantages. Lifetime duration of the UV LED without replacement is up to a few tens of thousands of hours. Their work is not associated with the release of any hazardous substances, including ozone. Dimensions of UV LED is ten times smaller, which allows to count on a constructive variety of cleaners and most efficient use of UV radiation, depending on the application. UV LEDs power consumption is 20 times less than power consumption of UV lamps, and low voltage (4) electrical safety and possibility of autonomous operation. The use of LEDs requires a new approach to the design and appearance of new methods of calculation of the photocatalytic units, which in turn required the identification and analysis of factors that determine the efficiency of photocatalytic air purification. The photocatalyst efficiency is determined by the quantum yield of the reaction and photocatalyst spectrum. To ensure the greatest quantum yield, i.e. the effective operation of photocatalyst there is a need to provide the largest contact surface of the catalyst with UV radiation, and cleaning air. The quantum yield is defined as the ratio between the number of molecules formed or decomposed in the system per unit time and the number of photons absorbed by the system per unit time, at a given wavelength:

$$
\Phi=\frac{\frac{d N_{r}}{d t}}{A\left(\frac{d N_{h n(i n c)}}{d t}\right)}=\frac{\frac{d N_{r}}{d t}}{\frac{d N_{h n(\text { abs })}}{d t}},
$$

where $A$ represents the absorbed part of the incident flux.

Thus, the quantum yield shows the number of molecules transformed by absorption of a photon. Figure 3 (a) presents the experimental dependence of the quantum yield of $\mathrm{FC}$ decomposition of acetone vapor on $\mathrm{TiO}_{2}$ photocatalyst brand Hombikat UV-100. It is obvious that in the range of $300-365 \mathrm{~nm}$ the quantum yield is maximum and changes slightly. Taking into account problems of LEDs manufacturing and costs, it is advisable to use LEDs with a wavelength of $365 \mathrm{~nm}$.

In addition to the selection of the appropriate catalyst modification with a large specific surface, increase the contact area with the radiation is possible due to selection of the substrate shape where the photocatalyst is applied. The substrate also must transmit ultraviolet radiation, be lightweight, low-cost, non-fragile, allow air circulation. Figure 3 (b) shows some examples of substrates. As radiation sources, in the task it is proposed to use a UV light emitting LEDs. The main source parameters are: the spectral range of the radiation angle and radiation indicatrix and the power density. 


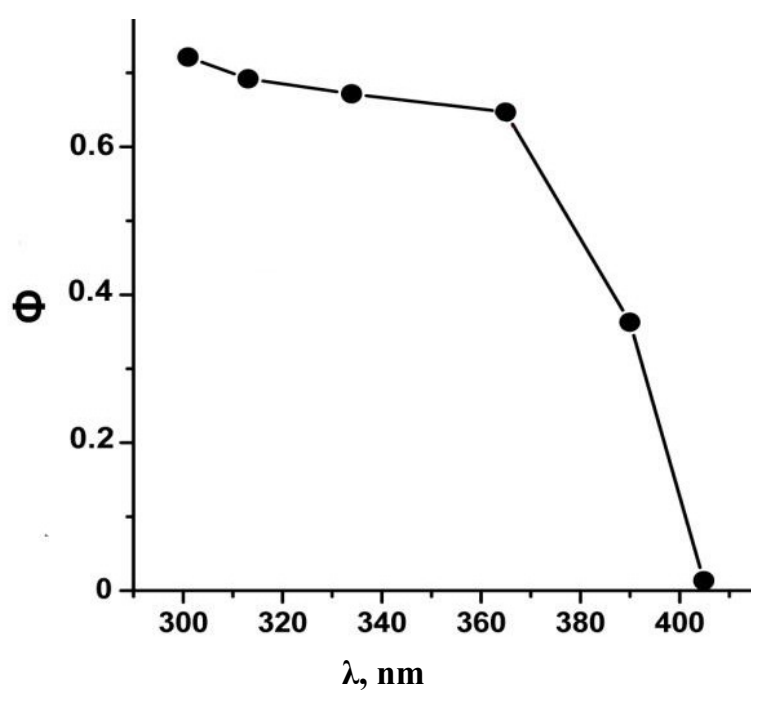

a

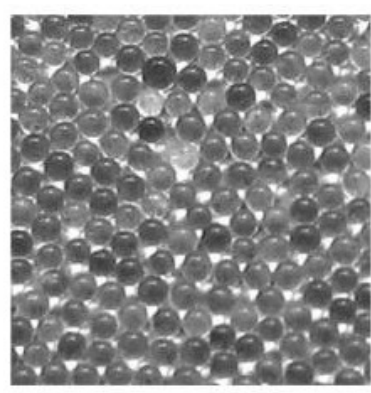

glass balls

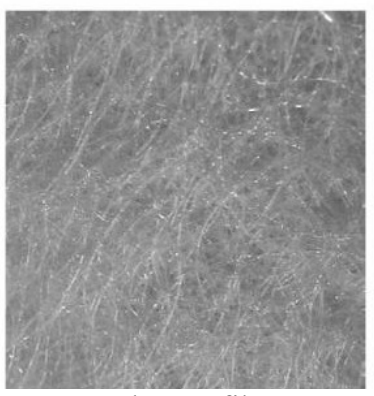

polymer fibers



fused glass balls

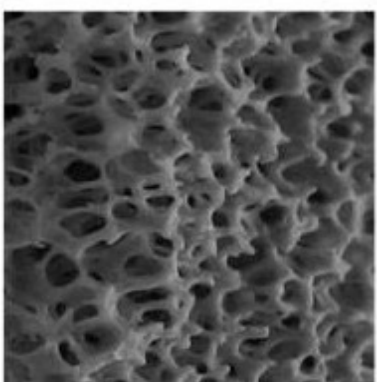

porous ceramics

b

Figure 3. Photocatalysis features: (a) - quantum yield dependence; (b) - examples of substrates

\section{Task}

The purpose of the case is development of the optical system of the photocatalytic unit providing the given requirements.

I. Task content

1. To execute marketing search of LEDs manufacturers (not less than five producers), draw up a comparative table of the characteristics of LEDs following the form and choose a LED that satisfies the requirements.

2. To determine the minimum number of LEDs that provides illumination of the photocatalytic substrate (screen) at the level of $5-20 \mathrm{mWt} / \mathrm{cm}^{2}$.

3. To offer an arrangement of LEDs that provides the most uniform illumination of the screen and allows to minimize the number of LEDs.

4*. To choose a material for the photocatalytic substrate.

5. To prepare the report and computer presentation.

6. To present results as an oral report.

II. Technical requirements

1. Light sources

Manufacturers: Nichia, Glacier, Fox Group and other. Group A: Radiation spectrum 300...400 nm; Group B: Radiation spectrum $300 \ldots 400 \mathrm{~nm}$.

2. Photocatalysis module structure: photocatalytic substrate (screen) with $\mathrm{TiO}_{2}$ layer; distance till the screen $140 \mathrm{~mm}$; screen size $2 \mathrm{~m}$. 


\section{Case 2. Design of amplitude fiber-optic converter (FOC) of reflective type \\ Preamble}

Modern engineering is characterized by intensive development of automated systems of monitoring and control of various technological processes. The operation of such systems requires the use of precise and reliable sensors to measure various physical quantities. Currently, to solve this problem the increasingly widespread use of fiber-optic sensors (FOS), which allow with high accuracy to measure various physical quantities (temperature, pressure, displacement, vibration, acoustic waves, electric and magnetic fields, fluid level, etc.) and, in addition, have small dimensions, weight, immunity to electromagnetic interference, and compatibility with modern fiber-optic transmission systems. For a broad introduction to measuring technique the best opportunity to have FOS with amplitude modulation of light signal, which are compared with the polarimetric phase FOS are the most simple and feasible design, and require minimal material and time costs of installation and operation. In many types of amplitude FOS the external influences cause a change in the position or shape of the movable (or deformable) element of the FOC, which in turn leads to a change (modulation) of the output optical signal of FOS. This ensures the convenient for further processing the presentation of information and explicit relation between the input and output variables. Traditionally, in the optical matching tasks FOC optical losses $A=f(z)$ while changing the distance $z$ between the optical fiber and the reflective sensing element (see the Figure 4) calculated by approximate formula, while it considers only the case of a uniformly illuminated flat reflective element:

$$
\begin{aligned}
& A=-10 \lg \left[\frac{1}{1+2\left(\frac{z}{2 a}\right) \operatorname{tg}(\arcsin (N A))}\right]^{2}, \\
& A=-10 \lg \left[\frac{a}{a+2 z(N A)}\right]^{2}
\end{aligned}
$$

where $a$-optical fiber core radius; $N A$ - optical fiber numerical aperture.

Task

1. To study applications of amplitude FOC of reflective type.

2. To determine the dependence of optical losses on the distance $z$ between the ends of the optical fibers and the reflecting element $A=f(z)$ : for single-fiber and dual-fiber FOC ( $A=-10 \lg \tau, \mathrm{dB} ; \tau=I_{\text {refl }} / I_{0}$, rel.u. $)$.

3 . To determine the range of greatest sensitivity ВОП $S=d A / d z$ from the graph.

4*. To determine why the achieved geometric dependence may not be quite accurate to describe the FOC characteristics.

5. To prepare the report and computer presentation.

6. To present results as an oral report.

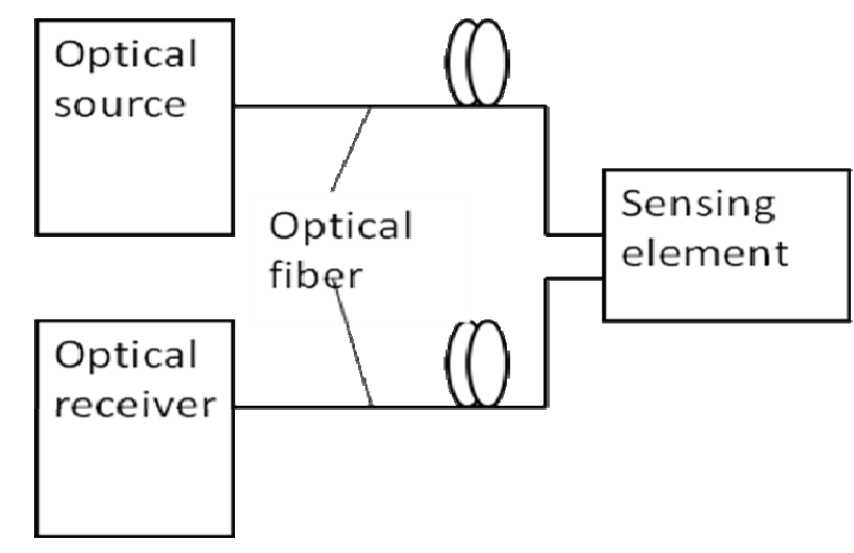

Figure 4. Fiber optic converter scheme 


\section{RESULTS}

The PBL cases were used during last 5 years for undergraduate students finishing their bachelor program in Applied and computer optics, more than 150 students in total. Each time groups performed tasks in different ways, used various design methods including heuristic methods (brainstorming, morphology analysis, etc.), and got absolutely disparate results. Sometimes students implemented the task all together, but in general they divided and made subtasks. Depending on a group background students deepened in calculations and modeling or otherwise proposed a set of design drawings. Often mediocre students demonstrated leadership and creative features, while excellent students stayed passive.

Analysis of assessment results has shown that in most cases students had low self-esteem. This phenomenon may be connected with different psychological and social factors as well as lack of experience to demonstrate and apply their skills and themselves in general. To provide more adequate and sensible studies similar PBL cases have to be applied in a curriculum more widely and a special database of PBL cases for optical engineering studies may be collected.

\section{CONCLUSION}

In this paper features and structure of a PBL case is shown. Assessment technology of learning outcomes is presented. Some cases of PBLs for optical engineering studies at the first cycle level are proposed. Results of the PBL cases application among ITMO University students are analyzed and recommendations for further PBL dissemination are formulated.

\section{REFERENCES}

[1] Judith F. Donnelly, Nicholas M. Massa, "The PBL Projects: Where we've been and where we are going," Proceedings of SPIE 9793 (2015).

[2] Nicholas M. Massa, Judith Donnelly, Fenna Hanes, "Student Reactions to Problem-Based Learning in Photonics Technician Education," Proceedings of SPIE 9289 (2013).

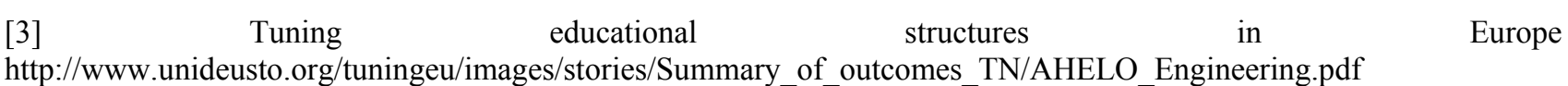

